\title{
Research on connectors' slip effect of prestressed concrete steel tank composite beam girder bridge
}

\author{
Xiaoxin Feng ${ }^{1,}$, Jiang Wang ${ }^{2, b}$ and Fan Gan ${ }^{3, c}$ \\ ${ }^{1,2,3}$ school of transportation, wuhan university of tecnology, wuhan, china \\ axiaoxinfeng1990@126.com, b470157079@qq.com, 547575286@qq.com
}

\begin{abstract}
Keywords: Hybrid girder bridge, composite beam, connectors, slip effect, the finite element method Abstract. Regarding the three spans Composite- Concrete hybrid continuous beam bridge as the research object, we use the general finite element software Midas civil on the cylindrical pin welding connection between concrete bridge panel and steel tank for simulation analysis.Analysis branch law of slip effect on the combined beam, and then sum up that nonuniform of slip effect on the concrete tank steel composite beam .Finally consider the comparative analysis of connection status in both ideal(no slip effect) and real (slip) condition, summarize the the influence of slip effect on stress and displacement of composite beam under the load, give advice on the connectors' design of concrete steel tank composite beam girder bridge.
\end{abstract}

\section{Introduction}

The prestressed concrete beam is used on the construction of side span and the part that stretches into the mid-span ; concrete and steel beam is introduced into the building of the middle section of the mid-span.All the above constitute the prestressed concrete steel tank beam combination girder bridge. This kind of hybrid girder bridge has improved the ability of the bridge span as well as the stress characteristics of the structure,thus making transition of stiffness more smooth. This kind of bridge has the advantages of small mid-span deflection and smooth driving .It has significant technical and economic benefits and social benefits,and is suitable for national conditions of our country's basic construction. There's no wonder that it will become one of the important developing direction of bridge structure.

The mid-span of mixed continuous girder bridge is under positive bending moment load, using concrete steel tank composite beam in middle span, and makes full use of the anti-pressure ability of concrete and anti-tensile properties of steel tank beam. The key technology of two kinds of material's synergistic effect is the ligation between the concrete slab and steel beam. The greater the connector's stiffness is, the more reasonable the location settings are, the synergistic effect between the two will be better.In practical engineering, the mechanical behavior between steel beam and concrete bridge deck is complex.Not only depended on the connector,it is also influenced by other factors, such as material, the cohesive force and the friction between the materials and so on[1]. This article made some assumptions, the finite element model is established to explore the influence of slip to prestressed concrete steel tank beam .

\section{Project Overview}

Regarding the three spans Composite- Concrete hybrid continuous beam bridge as the research object,its span arrangement for $45+80+45 \mathrm{~m}$, The facade is shown in Figure 1 .Side span and some of the middle span are concrete beam, which is variable cross-section beam single box double room, the standard cross-section shown in Figure 2. The middle part of the second span is concrete-steel tanks composite beam, the standard cross-section is shown in Figure 3. 


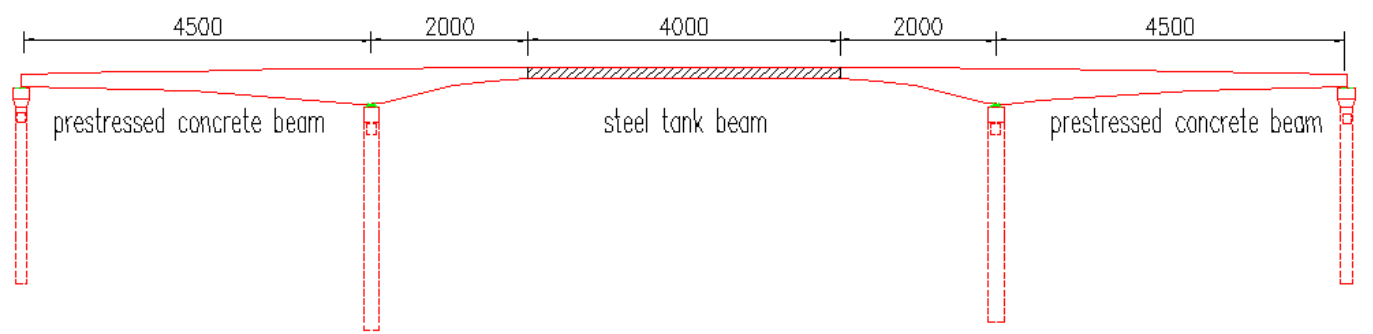

Figure 1 The elevation of hybrid continuous beam bridge(unit:cm)

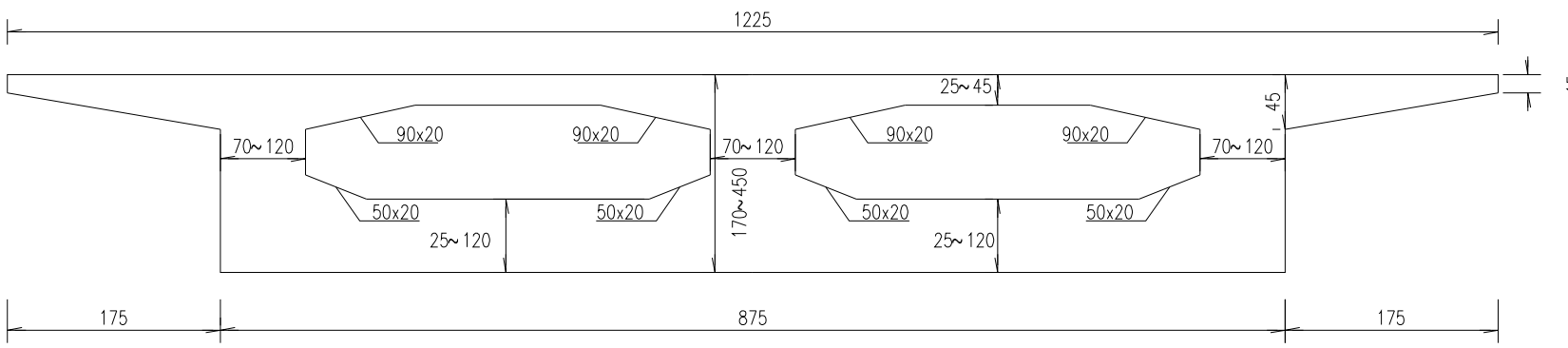

Figure 2 The concrete box beam standard section(unit:cm)

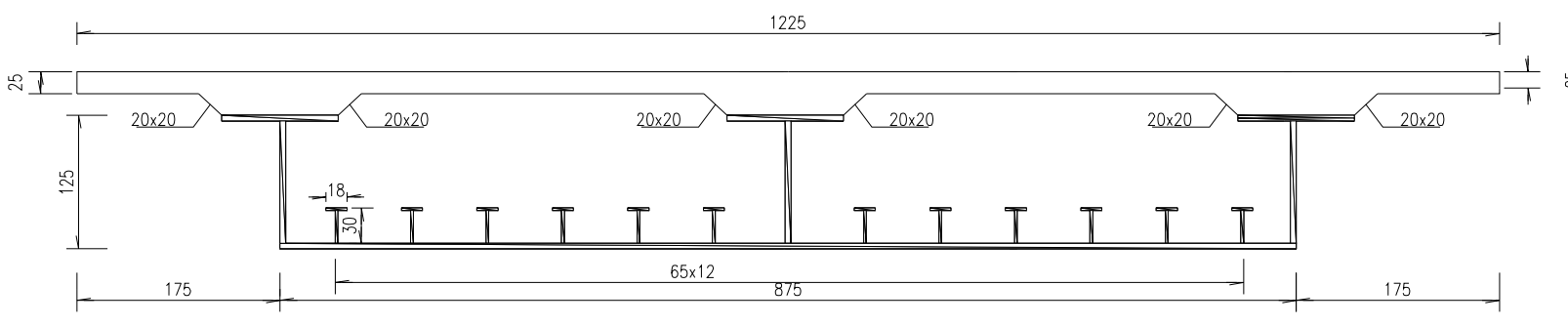

Figure 3 The standard section beam of steel - concrete composite (unit: $\mathrm{cm}$ )

\section{Connector Structure}

Shear connectors use $22 \mathrm{~mm}$ diameter cylindrical welding stud .which length is $180 \mathrm{~mm}$,k value of stud is 12 , material grade is $4.6, f=315 \mathrm{MPa}, \gamma=1.67$.Cylindrical stud welding materials conform to " Cheese head studs for arc stud welding." In the modeling process, in order to get the slip effect of concrete bridge decks and steel beams at separate establishment. according to result of calculation, $\mathrm{t}$, vertical stiffness of resilient connection $659400 \mathrm{kN} / \mathrm{m}$, the lateral line stiffness $253620 \mathrm{kN} / \mathrm{m}$, which meet the condition of deformation coordination.[2]

Concrete strength at the class of $\mathrm{C} 50, f \mathrm{c}=23.1 \mathrm{Mpa}, \mathrm{Ec}=34.5 \mathrm{GPa}$, steel tank is made from Q345, which $f \mathrm{a}=345 \mathrm{MPa}, \mathrm{Ea}=206 \mathrm{Gpa}$.

\section{The Finite Element Model}

This paper study the Slip effect to the prestressed concrete steel tank composite beam, the model was simplified. Made the following assumptions:

(1) ignore the bond strength and frictional force of interface between concrete bridge deck and the steel tank [3].

(2) Assuming that connection borne the slippage entirely between the two the connection is assumed to fully resist the division between concrete and steel bridge deck .

(3) ignore the connection deformation.[4]

We will compared the model results which consider slip effects and regardless of slip effect . 1) Slip effects model: namely, establish the bridge deck and steel tank beam respectively, and then use "flexible connection" to simulate the connection between the concrete deck and steel tank beam 2.) 
regardless of the slip effect model: the steel tank and concrete beams are considered as a whole part. Compression height is the equivalent sectional height.

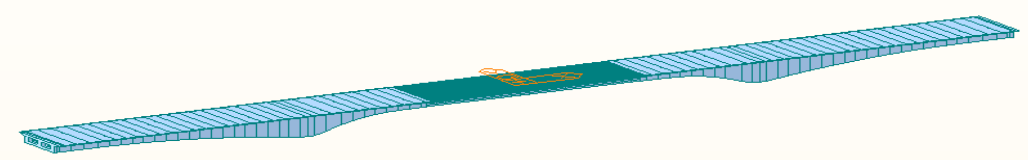

Figure 4 the finite element model of continuous girder bridge

\section{slip analysis of interface between concrete and steel tank}

4.1 distribution of slip value on composite beam

slip value distribution of composite beam is shown in fig. 5 ,while the bridge are during the using phase. As can be seen from the figure, the composite slip biggest value are not more than $0.115 \mathrm{~mm}$. Both end and mid-span of composite beam slip value is bigger, the slip value of the end reached 0.015 $\mathrm{m}$, the slip value of mid-span reached $0.115 \mathrm{~mm}$.
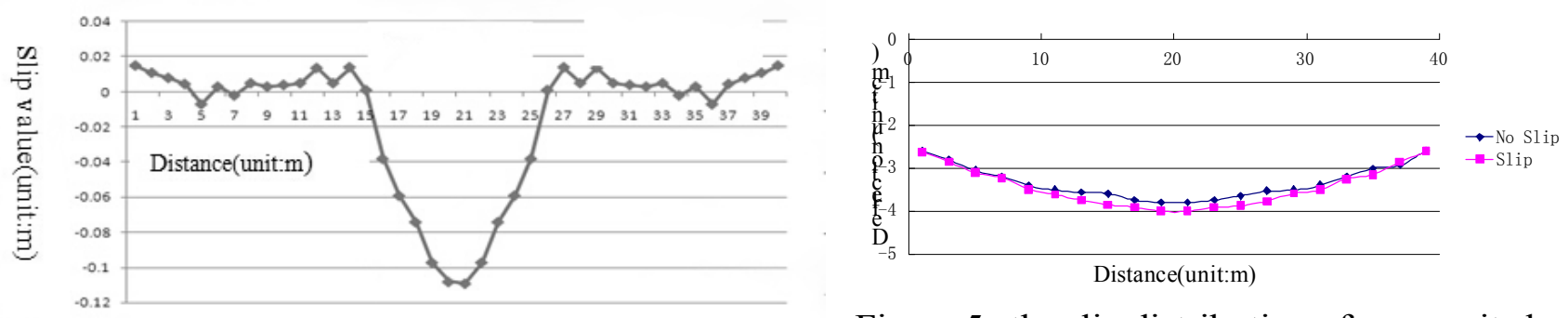

Figure 5 the slip distribution of composite beam

Figure 6 the bridge deflection under two conditions

4.2 Slip effect on the the impact of structure displacement

For the middle span when under vehicle load, consider slip effect, the main span mid-part maximum deflection and minimum deflection are respectively $1.11 \mathrm{~cm}$ and $-3.9 \mathrm{~cm}$, regardless of when the slip effect, the main span mid-span the maximum and minimum deflection were $1.27 \mathrm{~cm}$ and $-4.248 \mathrm{~cm}$. Margin of errors are $9.28 \%$, and $8.92 \%$,respectively. Compared the maximum and minimum displacement of composite beam considering slip effect and regardless of slip effect, respectively in fig.5. Can be drawn from the two figures, after considering the slip, the structure of the deflection caused by a certain influence, after considering the slip, deflection is larger. Slip effects more obvious to the region .

4.3 Slip effect on the the impact of structure stress Conclusion can be drawn from the fig. 7 and fig. 8

1) Considering Slip effect:
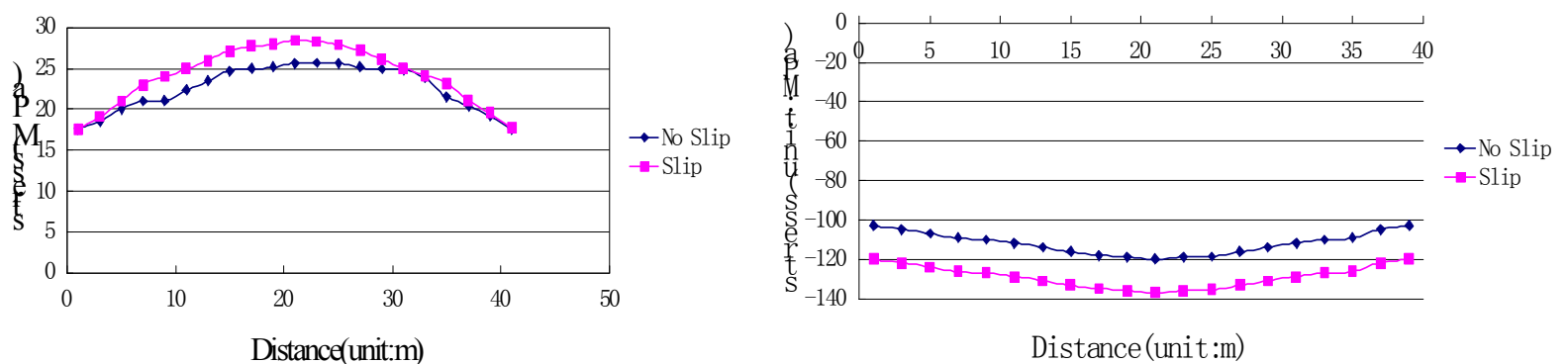

Figure 7 The stress of composite beam top edge Figure 8 The stress of composite beam lower edge 
In the long-term effects of the combination, the channel beam steel beams combined with the maximum compressive stress is $136.8 \mathrm{Mpa}$, occurs on the edge, the maximum tensile stress is $27.8 \mathrm{Mpa}$, occurs at the beam edge steel tanks.

2) Without considering slip effect:

In the combination for long-term load effects, the steel tank beam composite beam maximum compressive stress is $118.4 \mathrm{Mpa}$, occurs on the lower edge of steel tank beam, the maximum tensile stress is $25.7 \mathrm{Mpa}$, occurs on the top edge of steel tanks.

\section{Conclusion}

Beginning with building the models of the MIDAS steel tank composite beams with considering the slip effect and without regarding to the slip effect, the influences of the slip for the prestressed concrete steel tank composite beams are researched by comparing with the result of model calculation. Specifically, this paper made the following several aspect:

The slip distribution at the junction of the concrete and the steel tank: the slip value which is at the mid-span is greater than the slip value at other areas of the steel composite beams. By reference to the bending moment diagram of the steel tank composite beams, we can know that the slip value changes over the value of the bending moment. In general, the bigger the value of the bending moment in the steel composite beams, the greater the slip value. According to this rule, connectors should be arranged centrally at the area that the value of the bending moment is bigger. And connectors at the area that has the smaller value of the bending moment just need to be arranged scientifically.[5]

The influences of slip for deflection: the deflection of the structural is influenced by considering the slip. The deflection value will be bigger, and there will be a significant impact on the mid-span.

The influences of slip for stresses: When considering the slip, the maximum tensile stress in the steel tank's lower margin has about a 7.65 percent higher risk than that in which the slip isn't considered. Besides, taking the slip into account, we find the maximum pressure stress in the steel tank's upper margin has about a 13.4 percent higher risk than that in which the slip isn't considered. It shows the tensile stress in the steel tank's lower margin and the pressure stress in the steel tank's upper margin become greater because of the slip. Due to the influence, the bonding strength between the steel tank and the concrete bridge deck should be ensured during the design process.

\section{References}

[1] ZhenHua Mei, Shaowei Hu. Research on the effects of bending strength slip effect on composite beams , journal of solid mechanics, 2010 (31), 233-237

[2] Lixin Fang,Qigen Song. Partial shear connectors under elastic stiffness and ultimate strength calculations . Industrial construction. 2000.30 (1) : 47-50.

[3] Qinger Deng . Large span continuous composite box girder bridge fittings design method research . Shanghai, TongJi university, 2007

[4]Zona A, Ragni L, Dall A A. Finite element formulation for geometric and material nonlinear analysis of beams prestressed with external slipping tendons. Finite Elements in Analysis and Design. 2008, 44(15): 910-919.

[5]Feifei Sun, Guoqiang Li. Considering slip of shear lag and shear deformation analytical solutions of a steel concrete composite beams . Journal of engineering mechanics, 2005, 22 (2) : 96-103 